\title{
Exploring cellular uptake of iron oxide nanoparticles associated with rhodium citrate in breast cancer cells
}

This article was published in the following Dove Press journal:

International Journal of Nanomedicine

2 August 2017

Number of times this article has been viewed

\author{
Natalia L Chaves' \\ Irina Estrela-Lopis ${ }^{2}$ \\ Julia Böttner ${ }^{2}$ \\ Cláudio AP Lopes' \\ Bruna C Guido' \\ Aparecido $\mathrm{R}$ de Sousa ${ }^{3}$ \\ Sônia N Báo' \\ 'Institute of Biological Sciences, \\ Department of Cell Biology, \\ University of Brasília (UnB), Brasília, \\ Brazil; ' 2 Institute of Biophysics and \\ Medical Physics, University of Leipzig, \\ Leipzig, Germany; ${ }^{3}$ Institute of \\ Chemistry, Federal University of \\ Goiás, Goiânia, Brazil
}

\begin{abstract}
Nanocarriers have the potential to improve the therapeutic index of currently available drugs by improving their efficacy and achieving therapeutic steady-state levels over an extended period. The association of maghemite-rhodium citrate (MRC) nanoparticles (NPs) has the potential to increase specificity of the cytotoxic action. However, the interaction of these NPs with cells, their uptake mechanism, and subcellular localization need to be elucidated. This work evaluates the uptake mechanism of MRC NPs in metastatic and nonmetastatic breast cancer-cell models, comparing them to a nontumor cell line. MRC NPs uptake in breast cancer cells was more effective than in normal cells, with regard to both the amount of internalized material and the achievement of more strategic intracellular distribution. Moreover, this process occurred through a clathrin-dependent endocytosis pathway with different basal expression levels of this protein in the cell lines tested.
\end{abstract}

Keywords: maghemite, nanomaterials, cells uptake, endocytosis

\section{Introduction}

Over the years, the nanotechnology field has emerged as a promising approach for the development of novel diagnostic and therapeutic applications. ${ }^{1}$ The scale of the nanomaterials allows better access to biological sites. ${ }^{2-4}$ Among other applications, cancer-cell targeting would benefit greatly from highly specific and localized drug delivery. ${ }^{5-7}$

Iron oxide nanoparticles (NPs) hold great promise as diagnostic and therapeutic agents in oncology. Their intrinsic physical properties are particularly interesting for simultaneous drug delivery, molecular imaging, and such applications as localized hyperthermia. ${ }^{8,9}$ These technical features provide special perspectives to breast cancer treatment and diagnosis, especially because of the high incidence, drug resistance, and recurrence risk related to this disease. ${ }^{10-12}$

Current studies with maghemite (an iron oxide compound) NPs have demonstrated in vitro- and in vivo-specific cytotoxic action for target cells, indicating these NPs are a promising option for drug delivery. ${ }^{13-15}$ Maghemite-rhodium citrate (MRC) NPs have been recently tested, and showed colloidal stability and antitumor activity in breast cancer cells. ${ }^{16-18}$ However, MRC interaction with cells, their uptake mechanism, and subcellular localization are not understood.

Despite remarkable advances in nanoscience, relatively little is known about the intracellular destination and mechanism of action of NPs. This research field is particularly important in developing effective and safe delivery systems based on nanocomposites. NPs induce a large variety of intracellular responses, depending on
Correspondence: Sônia N Báo

Department of Cell Biology, Institute of Biological Sciences, University of Brasília (UnB), Campus Universitário Darcy Ribeiro, Brasília 70910-900, Brazil

Tel +55 6l 31073122

Email snbao@unb.br 
their physicochemical properties, intracellular concentration, duration of contact time, subcellular distribution, and interactions with biological molecules. ${ }^{19,20}$

Cellular uptake of NPs includes endocytic pathways, such as pinocytosis, clathrin or caveolin involvement, and clathrin/caveolin-independent internalization. ${ }^{21}$ Each of these processes involves distinctive mechanisms and molecules. Different endocytic routes may be correlated with cell-uptake velocity and cytotoxicity in cells. ${ }^{22}$ The physicochemical properties and surface reactivity of NPs are essential in determining the endocytosis pathway. In addition, cell types and their differentiation states may also determine the choice of route. The size and shape of the particles are important parameters with regard to the space available in these endocytic compartments. ${ }^{19,23,24}$

In the present study, the uptake and distribution of the most stable NPs composition based on maghemite were analyzed in vitro in different cell lines. Moreover, we evaluate the mechanism of endocytosis and discuss the uptake efficiency of MRC NPs in different cell lines: human breast cancer cell lines (MCF7 and MDA-MB231) and human nontumor mesenchymal cells (HNTMCs). We focused mainly on NPs interactions with different cells. We concluded that MRC NPs uptake in breast cancer cells is more effective than in normal cells with regard to both the amount of internalized nanomaterial and the achievement of more strategic intracellular distribution. Overall, our study demonstrates that cellular response after exposure to MRC NPs varies among cell lines and that different basal expression levels of clathrin in cells can define the biological pathway of MRC NPs and their uptake efficacy. This phenomenon can be potentially exploited for nanotherapeutic delivery.

\section{Materials and methods}

\section{Reagents and equipment}

Magnetic fluids used were synthesized by the coprecipitation method of $\mathrm{Fe}^{2+}$ and $\mathrm{Fe}^{3+}$ ions in alkaline medium and subsequently oxidized by bubbling oxygen. The functionalized fluids of MRC NPs and citrate-loaded maghemite (MC) NPs were obtained by adsorption experiments. MRC with 59.6 $\mu \mathrm{M}$ of $\gamma-\mathrm{Fe}_{2} \mathrm{O}_{3}$ and $2.85 \mu \mathrm{M}$ of $\mathrm{RC}, \mathrm{MC}$ with $64.7 \mu \mathrm{M}$ of $\gamma-\mathrm{Fe}_{2} \mathrm{O}_{3}$ and $2.55 \mu \mathrm{M}$ of $\mathrm{RC}$ and $2.513 \mathrm{mM} \mathrm{Rh}_{2}\left(\mathrm{H}_{2} \mathrm{Cit}\right)_{4}$ were synthesized at the Institute of Chemistry of Federal University of Goiás (Goiânia, Brazil). For cell-culture maintenance, we used DMEM, RPMI, FBS, and 0.25\% trypsin-EDTA (all from Thermo Fisher Scientific, Waltham, MA, USA) and Leibovitz L15 (Sigma-Aldrich, St Louis, MO, USA).

The antibodies used in this study were monoclonal anti- $\beta$-actin produced in mice, monoclonal anticlathrin heavy chain produced in mice, polyclonal anti-caveolin 1 produced in rabbits (Sigma-Aldrich), and IgG HRPconjugated antimouse and antirabbit (Sigma-Aldrich). The reagents used throughout the work were: MTT, BoDipy FL C-lactosylceramide ( $N$-[4,4-difluoro-5,7-dimethyl-4-bora3a,4a-diaza- $s$-indacene-3-pentanoyl]), sphingosyl 1- $\beta$-Dlactoside and transferrin from human serum, fluorescein conjugate (Thermo Fisher Scientific), methyl- $\beta$-cyclodextrin (MßCD; Sigma-Aldrich), Pitstop 2 (Abcam, Cambridge, UK), and bicinchoninic acid (Thermo Fisher Scientific). For Western blot analyses, we used a protease inhibitor (Hoffman-La Roche, Basel, Switzerland). The development was made with Amersham ECL prime Western blotting detection reagent, and image acquisition and analyses were performed with an Image Quant LAS 4000 (GE Healthcare, Little Chalfont, UK).

Ultrastructural analyses were performed with transmission electron microscopy (TEM, JEM-1011; JEOL, Tokyo, Japan) operating at $100 \mathrm{kV}$ and field-emission scanning electron microscopy (SEM, JSM-7000F; JEOL). Absorbance reading was performed using SpectraMax M5 equipment, and data were analyzed by SoftMax Pro 5.2, both from Molecular Devices (Sunnyvale, CA, USA). Flow cytometry was performed with a FACSCalibur (BD Biosciences, San Jose, CA, USA), and data analysis was performed with FlowJo 5.2.7 (Tree Star, Ashland, OR, USA). Raman analyses were carried out by confocal Raman microspectroscopy (CRM, Alpha300R+; WITec, Ulm, Germany). Statistical analyses and graphs were performed using GraphPad Prism 5 software.

\section{Cell culture}

The human breast cancer cell lines MCF7 and MDA-MB231 were obtained from the American Type Culture Collection and cultured in DMEM and Leibovitz L15 medium without $\mathrm{CO}_{2}$, containing $1 \%(\mathrm{v} / \mathrm{v})$ penicillin-streptomycin and $10 \%(\mathrm{v} / \mathrm{v})$ heat-inactivated FBS, respectively. FBS and penicillin-streptomycin were obtained from GIBCO - Life Technologies, Carlsbad, CA, USA. Primary cultures of HNTMCs from dental pulp were obtained from health volunteers, who provided informed consent, and with approval from the human ethics committee of the University of Brasilia (104934/2008). HNTMCs were cultured with DMEM and supplemented with $10 \%(\mathrm{v} / \mathrm{v})$ heat-inactivated fetal bovine serum and $1 \%(\mathrm{v} / \mathrm{v})$ penicillin-streptomycin.

\section{NPs characterization}

Diameter distribution and surface charge of the NPs were analyzed by a Zetasizer Nano ZS (Malvern Instruments, 
Malvern, UK) using a technology called dynamic light scattering, which enables estimation of average particle diameter and distribution. Assays were performed at $25^{\circ} \mathrm{C}$. Magnetic fluids were characterized by their loading and hydrodynamic diameter in water and diluted with culture medium (DMEM, 10\% FBS). Readings were taken immediately after dilutions and after 12 hours of incubation.

\section{Transmission electron microscopy}

For ultrastructural analysis of MRC NPs uptake, $8 \times 10^{5} \mathrm{MCF} 7$ and MDA-MB231 cells were plated in six-well plates, and after adhesion, cells were exposed to NPs $(200 \mu \mathrm{M})$ for 6 hours. Cells were then washed with PBS and fixed with Karnovsky's fixative (2\% glutaraldehyde, $2 \%$ paraformaldehyde, $3 \%$ sucrose, $0.005 \mathrm{M}$ calcium chloride in sodium cacodylate buffer $0.1 \mathrm{M}$ ) overnight at $4^{\circ} \mathrm{C}$. Subsequently, cells were washed with $0.1 \mathrm{M}$ sodium cacodylate buffer $(\mathrm{pH}$ 7.2) and postfixed for 30 minutes with $1 \%$ osmium tetroxide and $0.8 \%$ potassium ferricyanide in sodium cacodylate buffer and $5 \mathrm{mM} \mathrm{CaCl}_{2}$. Cells were then washed twice with water and then contrasted with $0.5 \%$ uranyl acetate at $4^{\circ} \mathrm{C}$. Samples were then dehydrated in increasing gradients of acetone (30\%-100\%) for 10 minutes each and embedded in Spurr's resin. Ultrathin sections were obtained with ultramicrometry (Leica Microsystems, Wetzlar, Germany) and analyzed with TEM and SEM.

\section{Raman microspectroscopy}

NPs distribution in MDA-MB231 and MCF7 cells was analyzed using CRM. A continuous laser beam was focused into a $300 \mathrm{~nm}$-size spot on a single cell with CRM (Alpha300R $\mathrm{R}^{+}$ equipped with a piezoelectric scanner (P-500; Physik Instrumente, Karlsruhe, Germany). The $532 \mathrm{~nm}$ laser excitation was used in combination with a water-immersion objective (63×/NA1.0; Carl Zeiss Meditec AG, Jena, Germany). Spectra were acquired using a charge-coupled device cooled to $-61^{\circ} \mathrm{C}$ (PI-Max; Princeton Instruments, Trenton, NJ, USA) behind grating (600 g. $\left.\mathrm{mm}^{-1}\right)$ spectrography (Acton; Princeton Instruments) with a spectral resolution of $4 \mathrm{~cm}^{-1}$. The cell surface was scanned with steps of $0.2 \mu \mathrm{m}$ and integrated over a time of about $0.1-0.3$ seconds at $36 \mathrm{~mW}$ laser power to produce high-quality cell mapping. Cells were plated on glass-bottom dishes (WillCo Wells, Amsterdam, the Netherlands) for Raman analysis and incubated with the MRC $(100 \mu \mathrm{M})$ NPs for 24 hours. Afterward, the cells were washed with PBS several times, fixed with 3.7\% formaldehyde in PBS for 30 minutes, and washed again. Cell spectra (at least five cells per sample) were obtained and analyzed.

\section{Quantification of cellular uptake}

Cells in the growth medium containing $100 \mu \mathrm{M}$ MRC were fixed in Karnovsky's fixative, postfixed in 1\% osmium tetroxide for 1.5 hours, dehydrated, and embedded in resin as previously described. The samples were then cut into slices of $0.3-0.6 \mu \mathrm{m}$ thickness from resin-embedded cells. Elemental analysis by energy-dispersive spectroscopy was then performed under high vacuum using SEM operating at $15-20 \mathrm{kV}$. The sections were imaged with secondary electrons for subsequent demarcation of cells, followed by induction, collection, and analysis of X-ray spectra from the selected areas. Assessment of intracellular iron was carried out with strictly the same acquisition settings for all samples. Moreover, micrographs acquired by TEM were used to quantify the mean of intracellular NPs with the software ImagePro Plus (Media Cybernetics, Rockville, MD, USA).

\section{Endocytosis study}

The clathrin and caveolin inhibitors - Pitstop $2(20 \mu \mathrm{M})$ and M $\beta C D(20 \mu \mathrm{M})$ - were administered in MDA-MB231 cell culture for 30 minutes. As a positive control for endocytosis, we used ferritin associated with Alexa 488 (clathrindependent endocytosis) and lactosylceramide conjugated to BoDipy (caveolin-dependent endocytic pathway). Quantification of cells containing NPs, control or treated with endocytic pathway inhibitors, was performed by flow cytometry. For Western blot, MDA-MB231, MCF7, and HNTMCs $\left(10^{6}\right)$ were grown in flasks. Fresh medium with $100 \mu \mathrm{M}$ MRC was added to the flasks, which were incubated for 6 hours at $37^{\circ} \mathrm{C}$. Cells were rinsed three times in ice-cold PBS, and protein extraction was performed with lysis buffer (50 mM Tris, pH 7,4; $150 \mathrm{mM} \mathrm{NaCl;} 5 \mathrm{mM}$ EDTA and 1\% Triton X-100 and protease-inhibitor cocktail). Lysates were centrifuged $\left(10\right.$ minutes, $\left.4^{\circ} \mathrm{C}\right)$. Protein concentrations were determined by bicinchoninic acid assay. Total lysates $(20 \mu \mathrm{g})$ were separated by sodium dodecyl sulfate polyacrylamidegel electrophoresis in a 4\%-12\% gradient and transferred to a nitrocellulose membrane. Membranes were blocked with 5\% nonfat dry milk in Tris-buffered saline-Tween $0.1 \%$, followed by incubation with primary $(1: 1,000$ anticaveolin $1,2 \mu \mathrm{L} / \mathrm{mL}$ anticlathrin and 1:5,000 anti- $\beta$-actin) and secondary (goat antimouse and goat antirabbit HRP 1:5,000) antibodies. Development was performed with the ECL chemiluminescence kit. The experiment was repeated three times.

\section{Statistical analysis}

All graph values are plotted as means \pm SE. One-way analysis of variance was used to perform statistical pairwise 
comparisons among cell types. We assigned statistical significance for all tests at $P<0.05$.

\section{Results \\ NPs characterization}

MRC solution diluted in $\mathrm{H}_{2} \mathrm{O}$ had a mean hydrodynamic diameter of $119.5 \mathrm{~nm}$, with a polydispersity index (PDI) of 0.17 and $\zeta$-potential of $-35 \mathrm{mV}$, and similar values were maintained after subsequent measurements at different intervals. This nanocomposite diluted in culture medium showed a mean hydrodynamic diameter of $161 \mathrm{~nm}$ (PDI 0.17) and $165 \mathrm{~nm}$ (PDI 0.17) and $\zeta$-potential of $-12.9 \mathrm{mV}$ and $-10.6 \mathrm{mV}$ at 0 and 12 hours, respectively. The MC NPs in water kept a mean hydrodynamic diameter of $97 \mathrm{~nm}$ (PDI 0.2) and a mean surface charge of $-44.7 \mathrm{mV}$. In culture medium, the mean hydrodynamic diameter of these NPs was $411 \mathrm{~nm}$, with $\zeta$-potential of $-12 \mathrm{mV}$ and PDI of 0.37 ( 0 hours) and $309 \mathrm{~nm}$ and $-12 \mathrm{mV}$ and PDI of 0.28 (12 hours). MRC NPs showed stability in both water and culture medium. However, MC NPs were not stable in physiological fluids, such as culturemedium conditions. Both NPs formulations had surfacecharge and hydrodynamic-diameter alterations (Table 1). These changes were progressive with incubation time.

\section{NPs localization by transmission electron microscopy}

After 6 hours of exposure, HNTMC images showed some MRC NPs inside the cytoplasm (Figure 1A and D) and a substantial amount of these elements surrounding the cell-membrane surface (Figure 1D). Images of MCF7 and MDA-MB231 cells revealed MRC NPs often present within cytoplasm. It was possible to identify vesicles containing NPs derived from uptake through the cellular membrane, especially in MCF7 cells (Figure 1B and E). In MDA-MB231 cells, MRC NPs occurred in high concentrations, forming large NPs clusters (Figure 1C, E, and F). It was possible to visualize NPs within nuclei in MCF7 and MDA-MB231

Table I Nanoparticle characterization

\begin{tabular}{|c|c|c|c|c|}
\hline Types of nanoparticles & $\mathbf{T}\left({ }^{\circ} \mathbf{C}\right)$ & HD (nm) & PDI & $\mathrm{mV}$ \\
\hline $\mathrm{MRC} \mathrm{H}_{2} \mathrm{O}$ & 25 & $120 \pm 1$ & $0.17 \pm 0.01$ & $-35 \pm 6$ \\
\hline MRC DMEM - 0 hours & 25 & $161 \pm 2$ & 0.17 & $-13 \pm 2$ \\
\hline MRC DMEM - 12 hours & 25 & $166 \pm 3$ & $0.17 \pm 0.01$ & $-11 \pm 1$ \\
\hline $\mathrm{MC} \mathrm{H}_{2} \mathrm{O}$ & 25 & $97 \pm 1$ & $0.20 \pm 0.02$ & $-45 \pm 6$ \\
\hline MC DMEM - 0 hours & 25 & $411 \pm 15$ & $0.37 \pm 0.05$ & $-12 \pm 1$ \\
\hline MC DMEM - 12 hours & 25 & $310 \pm 7$ & $0.280 \pm 0.003$ & $-12 \pm 1$ \\
\hline
\end{tabular}

Note: Data presented as mean \pm standard deviation.

Abbreviations: T, temperature; HD, hydrodynamic diameter; PDI, polydispersity index; MRC, maghemite-rhodium citrate; MC, maghemite-citate; HD (nm), hydrodynamic diameter in nanometers; $\mathrm{T}\left({ }^{\circ} \mathrm{C}\right)$, temperature in degrees Celsius; DMEM, Dulbecco's Modified Eagle's medium. cells. However, the presence of NPs in HNMTC nuclei was not identified (Figure 1A, D, and G). Cytotoxicity hallmarks were observed in MCF7 and MDA-MB231 cells, such as karyorrhexis (Figure $1 \mathrm{H}$ and $\mathrm{I}$ ) and vacuoles (Figure $1 \mathrm{H}$ [arrowhead]). It is known that the occurrence of different sized NPs clusters among cell lines can happen during NPs dilution in culture medium, since the components and $\mathrm{pH}$ of culture media can alter their colloidal behavior and stability, favoring aggregation. ${ }^{25,26}$ MRC NPs were analyzed regarding hydrodynamic-diameter alterations after incubation with the three different culture media (L15, RPMI, and DMEM) used in this study, under the same conditions as in MRC treatment of the cells. The results excluded the influence of culture-medium type on the formation of bigger aggregates in MDA-MB231 cells and different uptake patterns observed in the three cell types studied (Figure S1).

\section{NPs translocation in MCF7 and MDA- MB23 I cells by confocal Raman microspectroscopy}

Uptake and translocation patterns of MRC NPs at the singlecell level were studied in MCF7 and MDA-MB231cell lines by means of label-free CRM. Raman spectra of MRC NPs dispersed in water and dried on quartz glass exhibited peaks that were characteristic of maghemite $\left(\gamma-\mathrm{Fe}_{2} \mathrm{O}_{3}\right)$ and hematite $\left(\alpha-\mathrm{Fe}_{2} \mathrm{O}_{3}\right)$ crystal structures (Figure 2$)$. The presence of two crystal phases can be explained by a laser-induced thermal effect that leads to phase transition from $\gamma$ - to $\alpha$-phase. ${ }^{27}$ The maghemite peaks at $360-370$ and $490 \mathrm{~cm}^{-1}$ were able to be assigned to $\mathrm{T}_{1 \mathrm{~g}}$ and $\mathrm{E}_{\mathrm{g}}$ modes of vibration. In hematite nanostructures of MRC NPs, the peaks at 210, 280, 488, and $600 \mathrm{~cm}^{-1}$ were able to be attributed to $A_{1 \mathrm{~g}}, E_{\mathrm{g}}, \mathrm{A}_{1 \mathrm{~g}}$, and $\mathrm{E}_{\mathrm{g}}$ modes, respectively. ${ }^{28}$ The two main peaks at 210 and $280 \mathrm{~cm}^{-1}$ were used as fingerprint peaks for the identification of the NPs in a biological environment. Figure 2 shows the basic spectra of different cell components of control MDAMB231 cells, together with their barcodes. The spectra were generated calculating the average of all spectra in regions of interest (eg, lipid droplets [LDs]) and then demixed using the Demix algorithm. Cluster analysis was also used to receive the basic spectra.

The nuclear region of cells was identified by Raman peaks at $788,1,097$, and $1,340 \mathrm{~cm}^{-1}$. The peak at $788 \mathrm{~cm}^{-1}$ was assigned to the $\mathrm{O}-\mathrm{P}-\mathrm{O}$ stretching mode of the DNA backbone. ${ }^{29}$ The Raman peak in the nucleus spectrum at $1,097 \mathrm{~cm}^{-1}$ was attributed to the $\mathrm{PO}_{2}^{-}$stretching mode of the DNA, ${ }^{30}$ and $1,340 \mathrm{~cm}^{-1}$ corresponded to guanine and adenine. ${ }^{29}$ The high-frequency region above $2,000 \mathrm{~cm}^{-1}$ contained mainly information about $\mathrm{C}-\mathrm{H}$ stretching modes 


\section{HNTMCs}
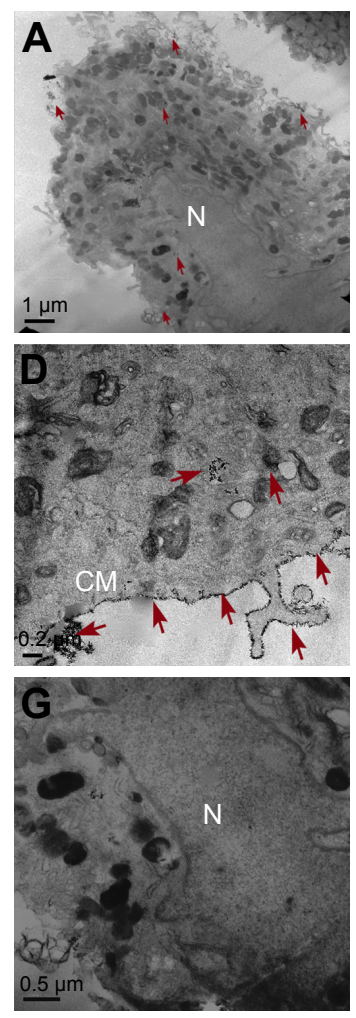

MCF7
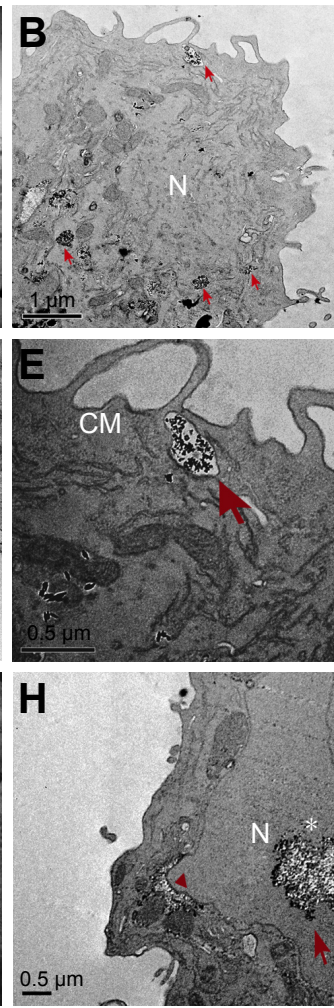

MDA-MB231
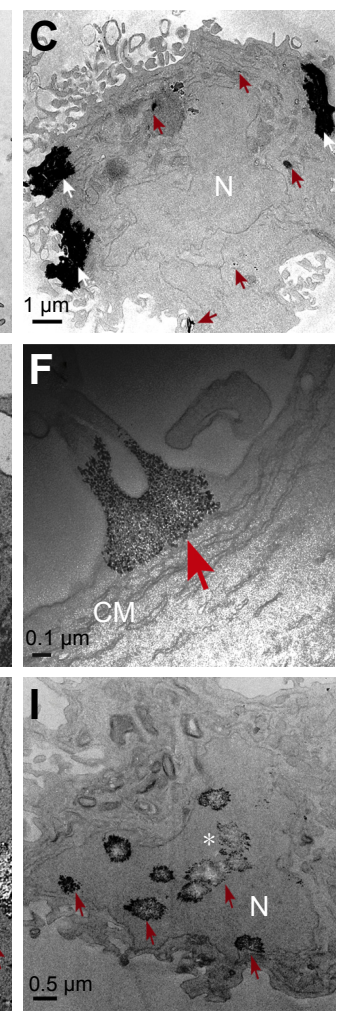

Figure I Electron micrography of cells exposed to maghemite-rhodium citrate nanoparticles (MRC NPs) for 6 hours.

Notes: Human nontumor mesenchymal cells (HNTMC) in first column showing some MRC NPs (indicated by red arrows) inside the cytoplasm (A, D), and a substantial amount of NPs surrounding the cell membrane (CM) surface (D). Images of MCF7 (second column) and MDA-MB23I (third column) cells revealed MRC NPs, often present within cytoplasm (B, C). MRC NPs within vesicles in MCF-7 cells (E). Bigger clusters of MRC NPs (white arrows) were found in MDA-MB23 I cells (C, F). MRC NPs reached the nucleus $(\mathrm{N})$ in MCF7 and MDA-MB23I cells $(\mathbf{H}, \mathbf{I})$ while free NPs in the nucleus were observed in HNTMCs (G). Red arrowhead shows perinuclear vacuoles in MCF7 cells $\mathbf{( H )}$. *Karyorrhexis evidenced in MCF7 (H) and MDA-MB23I (I) nuclei.
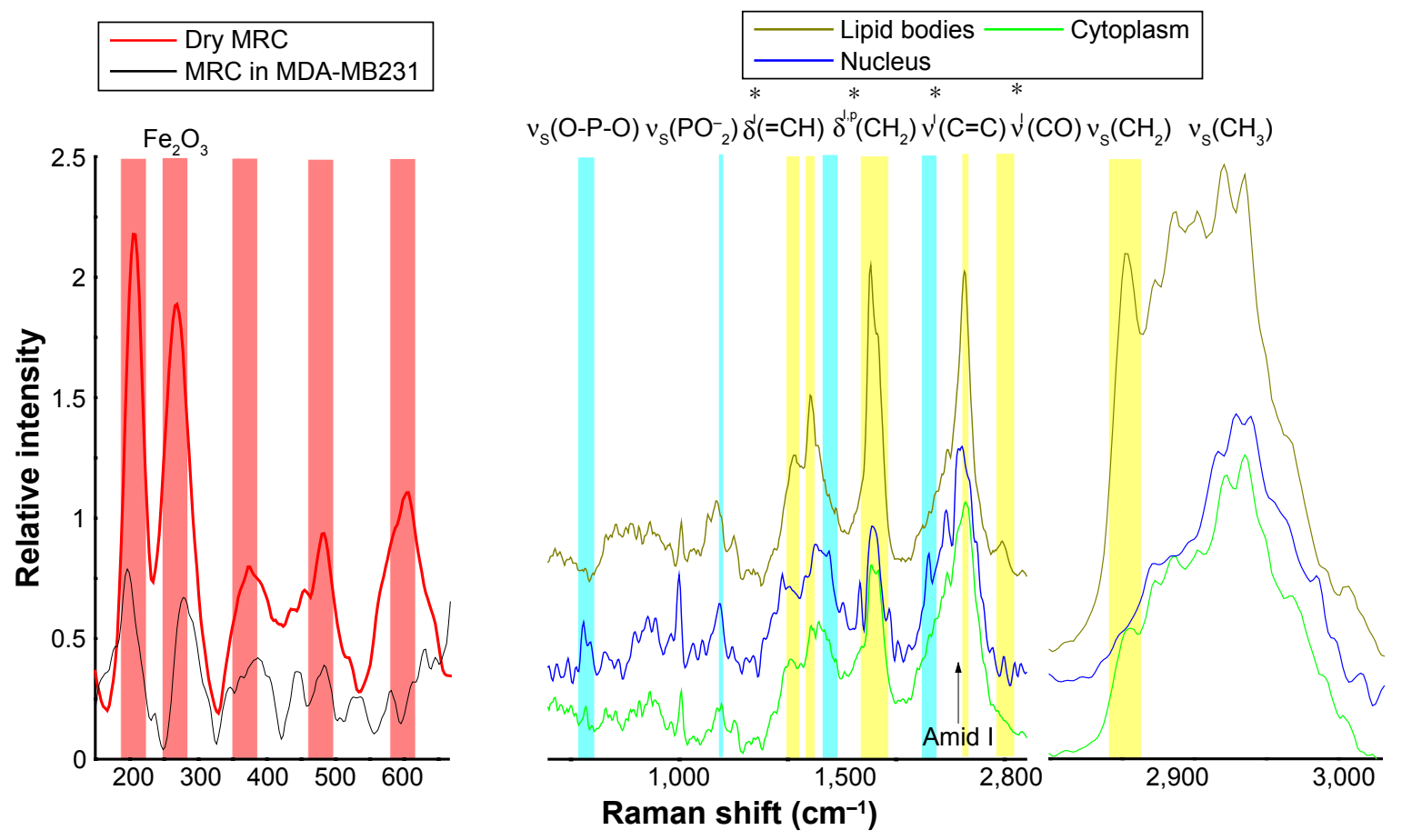

Figure 2 Raman spectra of maghemite-rhodium citrate (MRC) nanoparticles dried on quartz and in MDA-MB23I cells (left).

Notes: The average spectra of different cellular components of MDA-MB23I cells are shown with their characteristic barcodes (right). The assignment of typical vibrational bands is denoted. ${ }^{\mathrm{P}}$ and ${ }^{\prime}\left({ }^{*}\right)$ indicate protein and lipid vibrational modes, respectively. 
of methylene and methyl groups. In particular, the high-frequency region revealed the presence and proportion of $\mathrm{CH}_{3}$ and $\mathrm{CH}_{2}$ groups, which are important for identifying both lipid-rich and protein-rich regions. The symmetric stretch bands of $\mathrm{CH}_{2}\left(2,850 \mathrm{~cm}^{-1}\right)$ are much more intense in lipids than in the cytoplasm, due to a lower density of $\mathrm{CH}_{2}$ groups in proteins compared to lipids. In LDs, this stretching mode is very intense. The high specific adenine and guanine bands of nucleus, amide I of proteins and $\mathrm{CH}_{2}$ stretching, and $\mathrm{CO}$ and $\mathrm{C}=\mathrm{C}$ modes of LDs were able to be observed easily, and served as a tool for the label-free discrimination of cell chemical composition. ${ }^{27-29}$ Figure 3 shows the Raman images of NPs-exposed MCF7 and MDA-MB231 cells generated from molecular fingerprints of different cellular components and NPs. The NPs were fully internalized in both cell lines, showing their cytoplasmic location and heading in the direction of the nucleus after 24 hours. However, NPs revealed a different translocation pattern in MCF7 and MDA-MB231 cells. MRC NPs were found to be strongly aggregated intracellularly
(Figure 3B). This observation was in agreement with TEM data. Furthermore, small agglomerates with low NPs concentration were also localized in the peripheral cytoplasm, close to the plasma membrane. In MCF7 cells, NPs were distributed throughout the whole cell, but most NPs were detected as aggregates, ranging from 0.5 to $1 \mu \mathrm{m}$ in the perinuclear region (Figure 3). MRC NPs were found also to be partially localized with LDs. Additionally, alteration in cell morphology in both cell lines was observed when cells were exposed to MRC NPs. Most cells showed cytoplasmic vacuole formation and signs of nucleus degradation (Figure $3 \mathrm{~A}$ ).

\section{Endocytosis study}

In order to elucidate the endocytosis pathway involved in MRC NPs uptake, we performed a Western blot analysis to evaluate the expression levels of clathrin and caveolin, proteins that characterize two important endocytosis routes in both tumor and normal cells, both control and treated with NPs for 6 hours. MCF7 and MDA-MB231 tumor cells
A
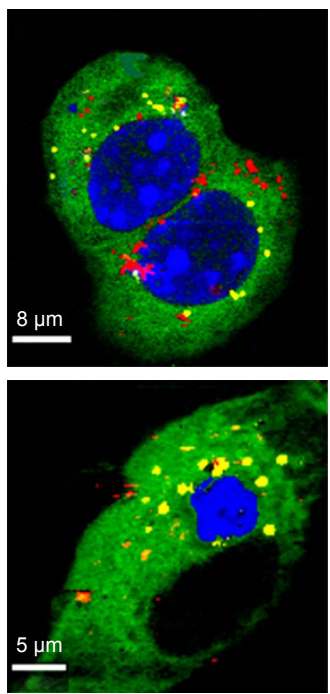

B

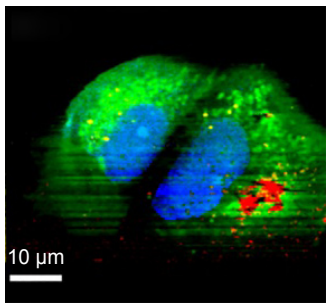

MCF7
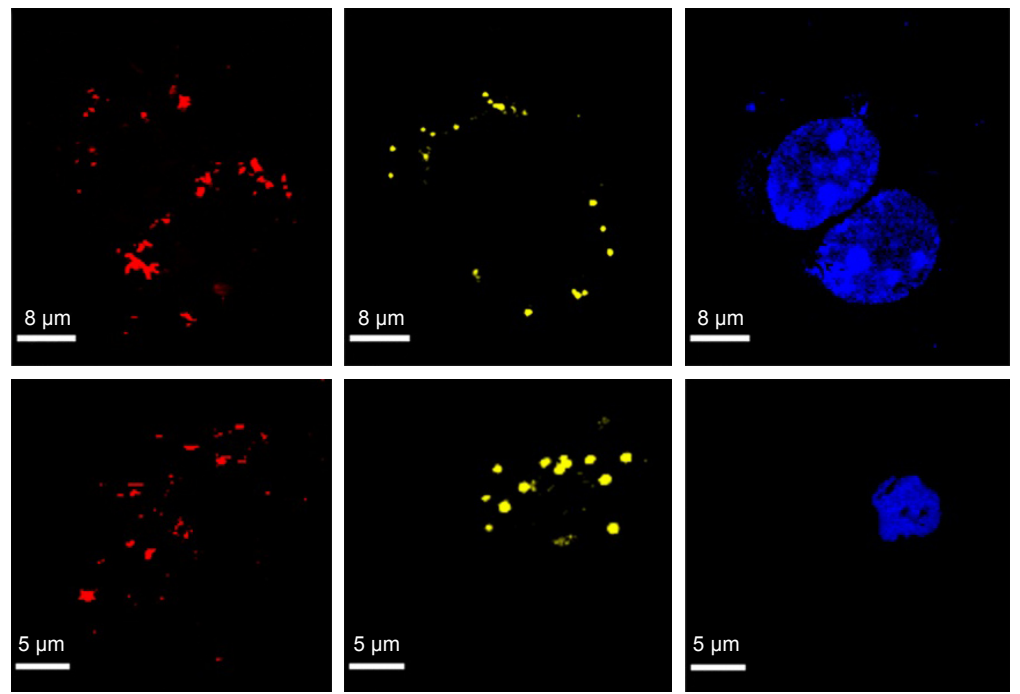

MDA-MB231
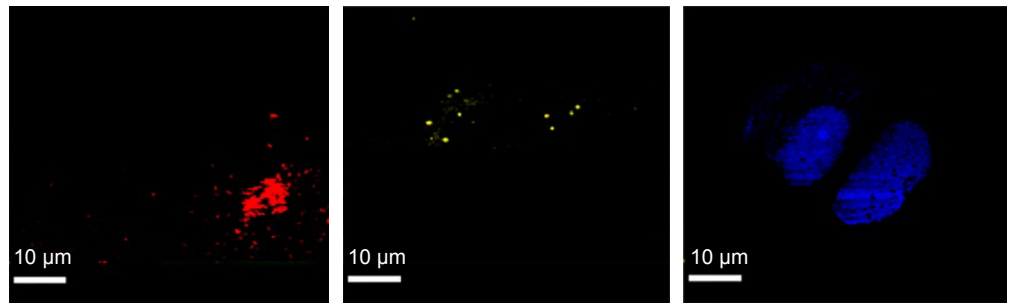

Cytoplasm MRC LDs $\bigcirc$ Nucleus

Figure 3 Intracellular maghemite-rhodium citrate nanoparticle (MRC NPs) location by confocal Raman microspectroscopy.

Notes: Images of different components of MCF7 (A) and MDA-MB23I (B) cells exposed to MRC NPs over 24 hours. The color-coded images on the left represent the overlapping of cytoplasm (green), nuclei (blue), lipids (yellow), and MRC NPs (red).

Abbreviation: LDs, lipid droplets. 
showed much higher basal levels of clathrin expression than HNTMCs (Figures 4A and S2). NPs treatment led to an increase in clathrin expression in all cell lines, but in a more pronounced way in HNTMCs and MCF7 cells (Figures 4A and S2). With regard to caveolin expression, no differences were observed between control and treated cells in any of the three cell lines, and as expected epithelial MCF7 cells presented much lower levels of caveolin. These results suggest that MRC NPs endocytosis is probably clathrin-dependent, due to its ubiquitous occurrence in eukaryotes, and since HNTMCs express lower basal levels of this protein, this can explain the better selectivity of MRC NPs for tumor cells compared to the normal cells used in this work. To test this hypothesis, clathrin- and caveolin-dependent endocytic pathways were individually inhibited with noncytotoxic doses (Figure S3) of Pitstop 2 and $\mathrm{M} \beta \mathrm{CD}$, respectively, in MDA-MB231 cells. This analysis was conducted by flowcytometry evaluation of forward-scatter and side-scatter parameters (Figure 4B). Forward-scatter and side-scatter intensities are proportional to cell size and intracellular density, respectively, enabling the distinction of cells that have internalized NPs (Figure 4A). Alexa 488-labeled transferrin and lactosylceramide BoDipy-LacCer were used as positive control for clathrin- and caveolin-dependent endocytosis, respectively. Uptake of Alexa 488-labeled transferrin was inhibited by $40 \%$ with Pitstop 2 treatment (Figure S4), and uptake of lactosylceramide was also significantly reduced in the presence of M $\beta C D$ (Figure S5), confirming the effective inhibition of these endocytic pathways. Incubation of MCR NPs-treated MDA-MB231 cells with Pitstop 2 resulted in about 30\% inhibition of NPs uptake. However, cell uptake of MRC was not reduced when the caveolin-dependent pathway was inhibited.

Taken together, these results corroborate the previous Western blot results, indicating that this NPs internalization seemed to happen in a clathrin-dependent way. Caveolin seemed not to play a role in the uptake of MRC NPs in these cell lines (Figure 4C).

A

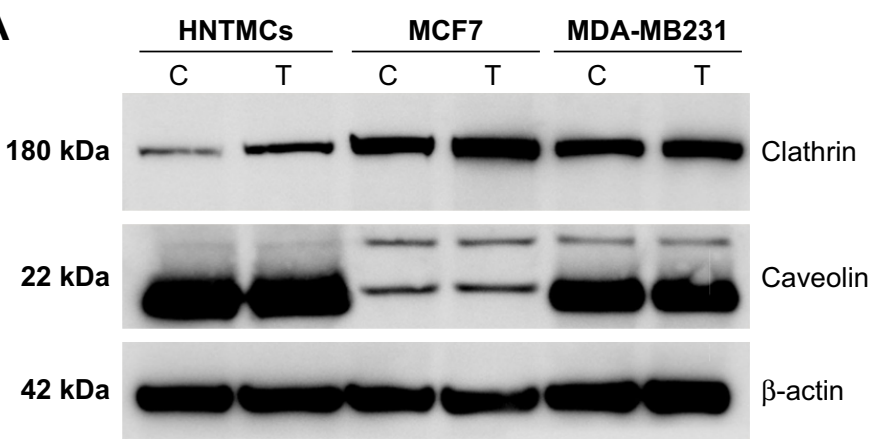

B

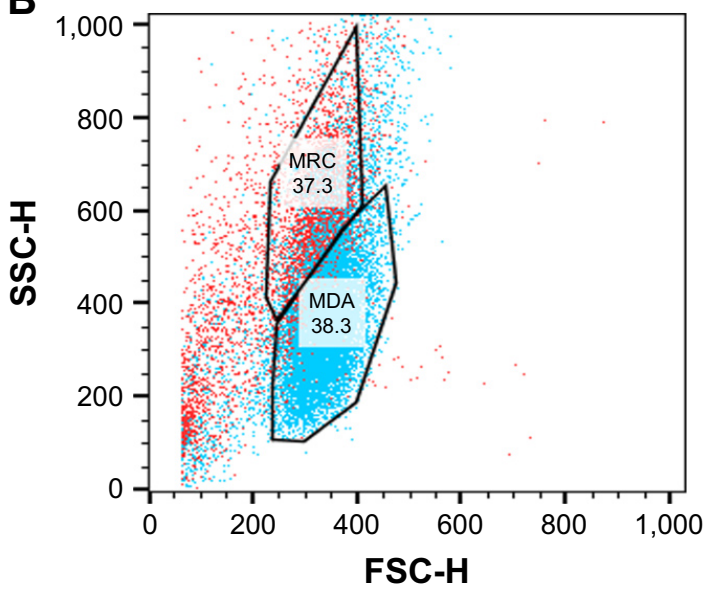

FSC-H

$\square$ MDA-MB231 Control

MDA-MB231 MRC
C

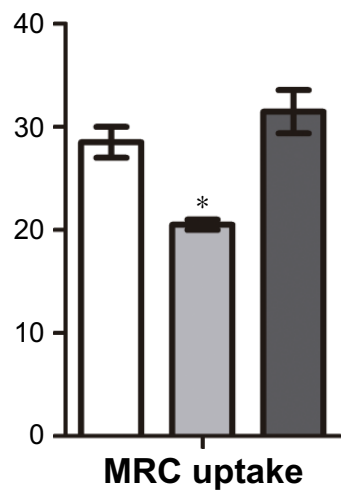

Figure 4 Endocytosis study.

Notes: (A) Western blot showing clathrin and caveolin expression in MDA-MB23 I, MCF7, and human nontumor mesenchymal cells (HNTMCs), both control (C) and treated (T). Sample loading was adjusted to equalize total protein. (B) Flow-cytometry light-scattering analysis showing MDA-MB23। cells with maghemite-rhodium citrate (MRC) nanoparticles (red) and without MRC nanoparticles (blue). (C) MRC uptake by MDA-MB23I was quantified after clathrin (Pitstop 2 ) and caveolin (M $\beta C D)$ inhibition. $* P<0.05$. 


\section{MRC NPs-uptake efficiency}

To evaluate MRC NPs-uptake efficiency in MDA-MB231, MCF7 and HNTMCs, SEM and X-ray microanalysis were performed. Cells were demarcated on samples after visualization with secondary electrons (Figure 5A and B), and the presence of osmium on the chemical spectra of the selected areas was used as a control to confirm that no extracellular material was considered in the analysis. This heavy-metal element is used during sample preparation for the fixation of cell membranes, providing resistance to the electron beam and contrast for image formation. ${ }^{31}$ Cellular levels of Fe in MDA-MB231 cells were significantly higher than in the other two cell lines. HNTMCs had the lowest

A

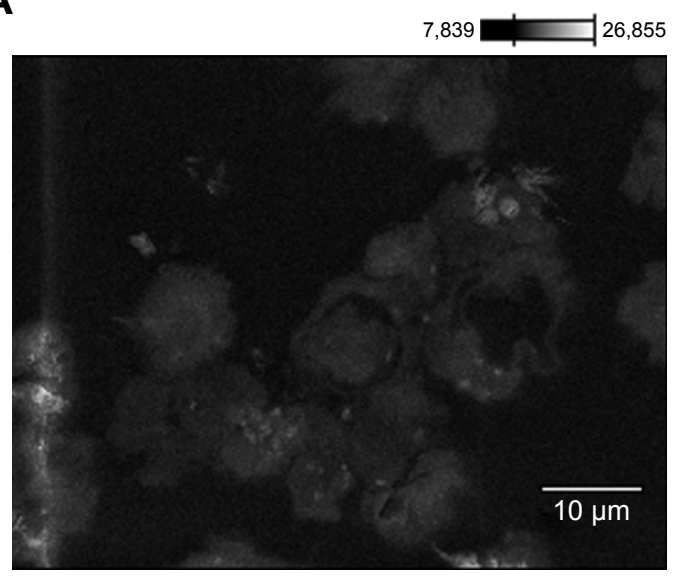

C

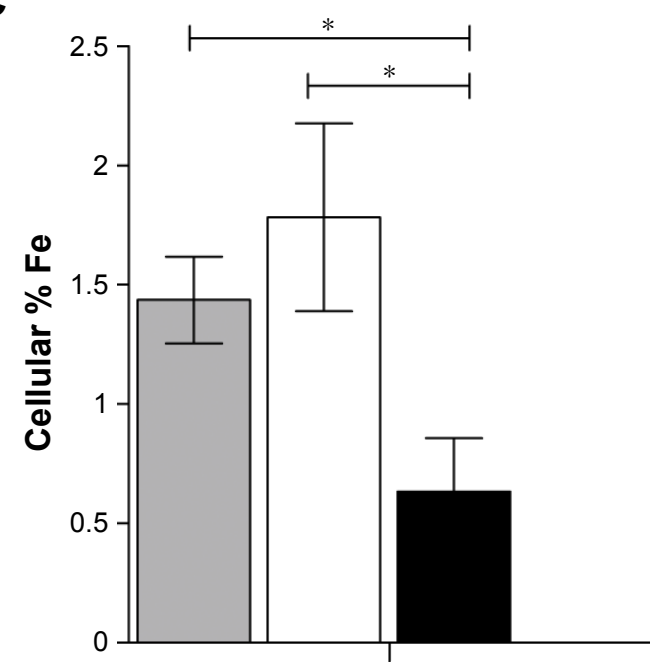

intracellular amounts of this element (Figure 5C). Similar results were obtained regarding the quantification of intracellular MRC $\left(\mathrm{MRC} / \mu^{2} \mathrm{~m}^{2}\right)$ NPs on TEM images (Figure 5D). These results reinforce the different patterns of intracellular NPs for breast cancer nonmetastatic (MCF7), breast cancer metastatic (MDA-MB231), and HNTMCs observed in TEM micrographs. Both methods were especially enlightening for this work to achieve clear NPs concentrations inside the cells (due to the slicing) and to exclude undesirable variables, such as cell-size variations and external NPs bound to the cell surface. Furthermore, the techniques applied here are label-free. The use of label-free dosimetry and imaging techniques is encouraged, since they are advantageous in

B

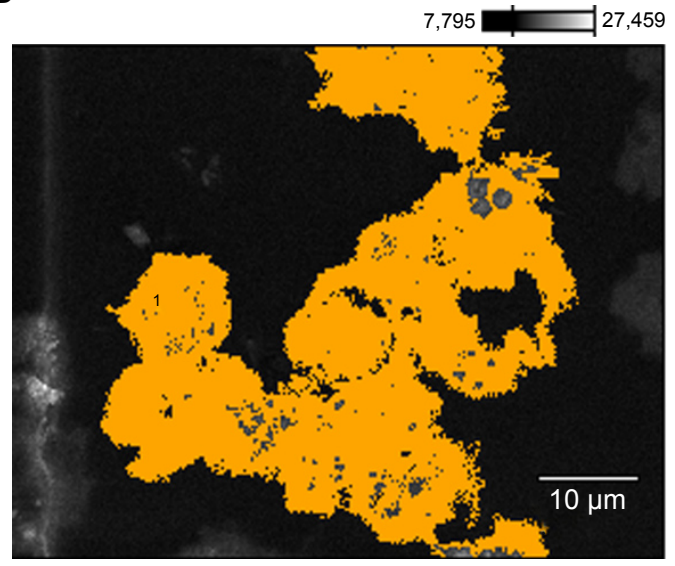

D

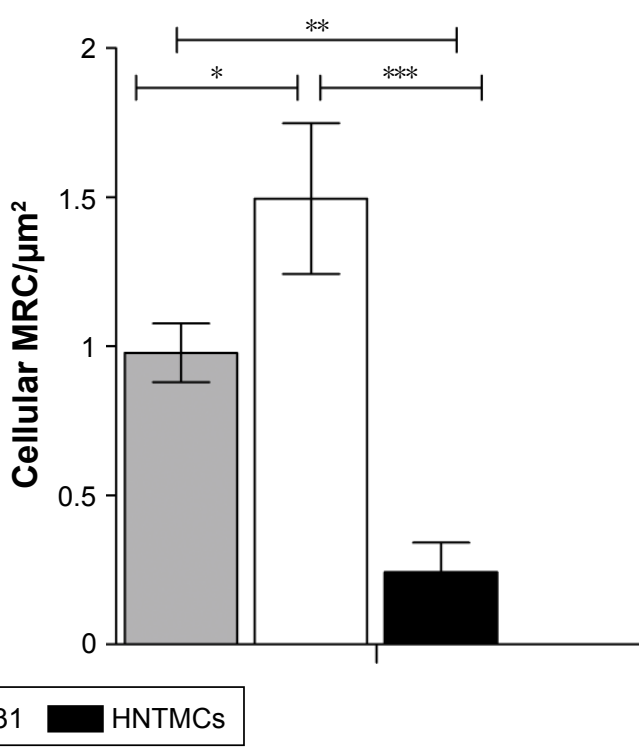

Figure 5 Maghemite-rhodium citrate nanoparticle (MRC NPs)-uptake efficiency in breast tumor cells (MCF7 and MDA-MB23I) and human nontumor mesenchymal cells (HNTMCs).

Notes: (A) Cells in a resin section imaged by scanning electron microscopy. (B) Cellular areas demarcated using Point \& Shoot acquisition mode (Thermo Fisher Scientific) and completely analyzed by energy-dispersive spectroscopy. (C) Percentage of iron in the analyzed cells. (D) Relative areas (\%) containing MRC NPs on transmission electron micrography of MDA-MB23I, MCF7, and HNTMCs. $* P<0.05$; $* * P<0.0 \mathrm{I}$; $* * * P<0.00 \mathrm{I}$. Magnification in $\mathrm{A}$ and $\mathrm{B} \times \mathrm{I}, 800$. 
the study of authentic nanomaterials. Such techniques as confocal laser microscopy and flow cytometry employed to NPs localization and quantification require fluorescent labels and dyes, which may significantly change the surface properties of nanomaterials, and thus misrepresent their cellular distribution and uptake. ${ }^{32} \mathrm{We}$ have demonstrated that MDA-MB231 and MCF7 cells had an uptake approximately three- and twofold higher than HNTMCs (nontumor cells), respectively (Figure 5B).

\section{Discussion}

We have shown preferential uptake of MRC agglomerates in MDA-MB231 and MCF7 cells that coincide with their high basal clathrin expression, which mediates endosomal internalization. The data found in our work are in accordance with studies showing that the uptake of particles of $500 \mathrm{~nm}$ diameter is mediated by clathrin-dependent endocytosis. ${ }^{33,34}$ Despite studies showing that internalization of particles smaller than $200 \mathrm{~nm}$ in diameter was mediated by clathrincoated pits, and when their size was increased, uptake shifted to caveolae-mediated internalization, ${ }^{35,36}$ however, these data conflict with other studies that estimated caveolae-dependent internalization of 50-80 nm-diameter NPs, while NPs of $120 \mathrm{~nm}$ diameter were internalized by clathrin-coated pits. ${ }^{37-39}$ Higher internalization is an index for more accumulation of drug molecules, which release slowly and have sustained effects on cancer cells. Internalization and prolonged retention of nanomedicine by tumor cells are desirable for more effective tumor killing and specific action. Previous studies have already estimated internalization of magnetic NPs of similar size in MDA-MB231, MCF7, ${ }^{40,41}$ and cells similar to HNTMCs. In vitro evaluation using cells similar to HNTMCs revealed less internalization of maghemite NPs compared to tumor cells (HeLa), ${ }^{42}$ consistent with our findings. Chithrani and $\mathrm{Chan}^{43}$ demonstrated that the endocytosis mechanism of gold NPs in MCF7 cells was clathrin-dependent. Furthermore, also in accordance with our work, higher uptake of iron oxide NPs by MDA-MB231 compared to MCF7 cells has been evidenced. ${ }^{44}$

The endocytosis process can potentially control many activities related to cancer-cell proliferation and migration. These processes require dynamic modulation of cell-surface proteins by endocytosis. Given this functional connection, it has been suggested that endocytosis is unregulated in cancer, resulting in different cell phenotypes. ${ }^{45}$ Therefore, further work is necessary to explore the role and regulation of clathrin associated with breast cancer-cell phenotype and cancer hallmarks directly.
MRC NPs reached the nuclear region in tumor cells only (MCF7 and MDA-MB231). A recent study demonstrated that cellular localization of drugs can determine their anticancer mechanism of action. In this context, compound translocation to the cell nucleus induces cell-cycle arrest in the $\mathrm{S}$ phase through triggering $\mathrm{p} 53$-mediated DNA damage response, showing higher anticancer efficacy than other formulations that remain localized in the cytoplasm. ${ }^{46}$ Since nuclear location is associated with more efficient action of antitumor drugs, these results show that MRC NPs potential as an antitumor compound must be explored. Furthermore, it is possible to suggest a selective action modulated by the natural design of NPs and cell features. Differences in particle-uptake efficiency can be explained by variations in cell-membrane composition and metabolic activity of the tested cells. ${ }^{39,47}$ The high metabolic activity of tumor cells can lead to overexpression of surface receptors, contributing to an increase in NPs uptake. ${ }^{48}$ In this case, clathrin expression may have favored MRC NPs uptake in breast tumor cells.

\section{Conclusion}

In the past few years, many studies have related different NPs size, composition, and charge to uptake processes and localization in cells. However, despite some works mentioning cell type as an important factor in evaluating this process, few experiments have compared single-NPs uptake in different cell lines. Our results demonstrated that cell type is a critical factor in NPs cellular interaction. The expression of different protein levels involved in endocytic pathways among cell types can define the route, mechanism, uptake efficiency, and intracellular distribution of NPs. Therefore, in vitro experiments using different cell lines are encouraged to validate cytotoxic studies. Our results suggest that MRC NPs are a promising nanomaterial, which may provide a convenient route for cellular targeting with great potential for clinical application in cancer treatment.

\section{Acknowledgments}

The authors acknowledge financial support from the CNPq, CAPES, FAP-DF, and FINEP. All authors contributed equally to this work.

\section{Disclosure}

The authors report no conflicts of interest in this work.

\section{References}

1. Azzawi M, Seifalian A, Ahmed W. Nanotechnology for the diagnosis and treatment of diseases. Nanomedicine (Lond). 2016;11(16): 2025-2027. 
2. Banks WA. From blood-brain barrier to blood-brain interface: new opportunities for CNS drug delivery. Nat Rev Drug Discov. 2016;15(4): 275-292.

3. Crawford L, Rosch J, Putnam D. Concepts, technologies, and practices for drug delivery past the blood-brain barrier to the central nervous system. J Control Release. 2016;240:251-266.

4. Upadhyay RK. Drug delivery systems, CNS protection, and the blood brain barrier. Biomed Res Int. 2014;2014:869269.

5. Mirkin CA, Meade TJ, Petrosko SH, Stegh AH. Nanotechnology-Based Precision Tools for the Detection and Treatment of Cancer. Heidelberg: Springer; 2015.

6. Pentenero M. Nanotechnology: a novel adjunctive aid to fight cancer. Oral Dis. 2017;23(3):273-275.

7. Maeda H, Nakamura H, Fang J. The EPR effect for macromolecular drug delivery to solid tumors: improvement of tumor uptake, lowering of systemic toxicity, and distinct tumor imaging in vivo. Adv Drug Deliv Rev. 2013;65(1):71-79.

8. Quinto CA, Mohindra P, Tong S, Bao G. Multifunctional superparamagnetic iron oxide nanoparticles for combined chemotherapy and hyperthermia cancer treatment. Nanoscale. 2015;7(29):12728-12736.

9. Iv M, Telischak N, Feng D, Holdsworth SJ, Yeom KW, Daldrup-Link HE. Clinical applications of iron oxide nanoparticles for magnetic resonance imaging of brain tumors. Nanomedicine (Lond). 2015;10(6): 993-1018.

10. Harmon TL, Harbuzariu A, Yang L, Gonzalez-Perez RR. Iron oxide nanoparticle-leptin receptor antagonist: a novel targeted adjuvant therapy for triple negative breast cancer. Proc Annu Meet Am Assoc Cancer Res. 2015;75(15 Suppl):3909.

11. Karakatsanis A, Christiansen P, Fischer L, et al. Super paramagnetic iron oxide nanoparticles for sentinel node detection in patients with breast cancer: experience from seven centres in Sweden and Denmark. Eur J Surg Oncol. 2016;42(9):S83.

12. Kossatz S, Grandke J, Couleaud P, et al. Efficient treatment of breast cancer xenografts with multifunctionalized iron oxide nanoparticles combining magnetic hyperthermia and anti-cancer drug delivery. Breast Cancer Research. 2015;17:66.

13. Estelrich J, Escribano E, Queralt J, Busquets MA. Iron oxide nanoparticles for magnetically-guided and magnetically-responsive drug delivery. Int J Mol Sci. 2015;16(4):8070-8101.

14. Jurado R, Frączek P, Droetto M, et al. Apomaghemite as a doxorubicin carrier for anticancer drug delivery. J Inorgan Biochem. 2016;157: 46-51.

15. Graczyk H, Bryan LC, Lewinski N, et al. Physicochemical characterization of nebulized superparamagnetic iron oxide nanoparticles (SPIONs). J Aerosol Med Pulm Drug Deliv. 2015;28(1):43-51.

16. Carneiro ML, Peixoto RC, Joanitti GA, et al. Antitumor effect and toxicity of free rhodium (II) citrate and rhodium (II) citrate-loaded maghemite nanoparticles in mice bearing breast cancer. J Nanobiotechnology. 2013;11:4

17. Chaves NL, Lopes CA, Carneiro ML, et al. Rhodium citrate associated with maghemite nanoparticles causes DNA fragmentation independently of caspases 3 and mediated by reactive oxygen species. J Nanomed Nanotechnol. 2015;6:312.

18. Peixoto RC, Miranda-Vilela AL, de Souza Filho J, et al. Antitumor effect of free rhodium (II) citrate and rhodium (II) citrate-loaded maghemite nanoparticles on mice bearing breast cancer: a systemic toxicity assay. Tumour Biol. 2015;36(5):3325-3336.

19. Zhang S, Gao H, Bao G. Physical principles of nanoparticle cellular endocytosis. ACS Nano. 2015;9(9):8655-8671.

20. Paulo CS, das Neves RP, Ferreira LS. Nanoparticles for intracellulartargeted drug delivery. Nanotechnology. 2011;22(49):494002.

21. Sahay G, Alakhova DY, Kabanov AV. Endocytosis of nanomedicines. $J$ Control Release. 2010;145(3):182-195.

22. Fröhlich $\mathrm{E}$. The role of surface charge in cellular uptake and cytotoxicity of medical nanoparticles. Int J Nanomedicine. 2012;7:5577-5591.

23. Nel AE, Mädler L, Velegol D, et al. Understanding biophysicochemical interactions at the nano-bio interface. Nat Mater. 2009;8(7):543-557.
24. Saie AA, Ray M, Mahmoudi M, Rotello VM. Engineering the nanoparticle-protein interface for cancer therapeutics. In: Mirkin CA, Meade TJ, Petrosko SH, Stegh AH, editors. Nanotechnology-Based Precision Tools for the Detection and Treatment of Cancer. Heidelberg: Springer; 2015:245-273.

25. Moore TL, Rodriguez-Lorenzo L, Hirsch V, et al. Nanoparticle colloidal stability in cell culture media and impact on cellular interactions. Chem Soc Rev. 2015;44(17):6287-6305.

26. Baca HK, Ashley C, Carnes E, et al. Cell-directed assembly of lipid-silica nanostructures providing extended cell viability. Science. 2006;313(5785):337-341

27. Chamritski I, Burns G. Infrared- and Raman-active phonons of magnetite, maghemite, and hematite: a computer simulation and spectroscopic study. J Phys Chem B. 2005;109(11):4965-4968.

28. Notingher I, Verrier S, Haque S, Polak J, Hench L. Spectroscopic study of human lung epithelial cells (A549) in culture: living cells versus dead cells. Biopolymers. 2003;72(4):230-240.

29. Notingher I, Green C, Dyer C, et al. Discrimination between ricin and sulphur mustard toxicity in vitro using Raman spectroscopy. $J R$ Soc Interface. 2004;1(1):79-90.

30. Movasaghi Z, Rehman S, Rehman IU. Raman spectroscopy of biological tissues. Appl Spectrosc Rev. 2007;42(5):493-541.

31. Wyroba E, Suski S, Miller K, Bartosiewicz R. Biomedical and agricultural applications of energy dispersive X-ray spectroscopy in electron microscopy. Cell Mol Biol Lett. 2015;20(3):488-509.

32. Collins AR, Annangi B, Rubio L, et al. High throughput toxicity screening and intracellular detection of nanomaterials. Wiley Interdiscip Rev Nanomed Nanobiotechnol. 2017;9(1):e1413.

33. Blechinger J, Bauer AT, Torrano AA, Gorzelanny C, Bräuchle C, Schneider SW. Uptake kinetics and nanotoxicity of silica nanoparticles are cell type dependent. Small. 2013;9(23):3970-3980.

34. Zhang Y, Hu L, Yu D, Gao C. Influence of silica particle internalization on adhesion and migration of human dermal fibroblasts. Biomaterials. 2010;31(32):8465-8474.

35. Rejman J, Oberle V, Zuhorn IS, Hoekstra D. Size-dependent internalization of particles via the pathways of clathrin- and caveolae-mediated endocytosis. Biochem J. 2004;377(1):159-169.

36. Suen WL, Chau Y. Size-dependent internalisation of folate-decorated nanoparticles via the pathways of clathrin and caveolae-mediated endocytosis in ARPE-19 cells. J Pharm Pharmacol. 2014;66(4):564-573.

37. Gratton SE, Ropp PA, Pohlhaus PD, et al. The effect of particle design on cellular internalization pathways. Proc Natl Acad Sci US A. 2008;105(33):11613-11618.

38. Patel LN, Zaro JL, Shen WC. Cell penetrating peptides: intracellular pathways and pharmaceutical perspectives. Pharm Res. 2007; 24(11):1977-1992.

39. Kettler K, Veltman K, van de Meent D, van Wezel A, Hendriks AJ. Cellular uptake of nanoparticles as determined by particle properties, experimental conditions, and cell type. Environ Toxicol Chem. 2014; 33(3):481-492.

40. Zhang Y, Yang M, Portney NG, et al. Zeta potential: a surface electrical characteristic to probe the interaction of nanoparticles with normal and cancer human breast epithelial cells. Biomed Microdevices. 2008;10(2):321-328.

41. Cai $\mathrm{Y}, \mathrm{Cao} \mathrm{C}, \mathrm{He} \mathrm{X}$, et al. Enhanced magnetic resonance imaging and staining of cancer cells using ferrimagnetic H-ferritin nanoparticles with increasing core size. Int J Nanomedicine. 2015;10:2619-2634.

42. Auffan M, Decome L, Rose J, et al. In vitro interactions between DMSA-coated maghemite nanoparticles and human fibroblasts: a physicochemical and cyto-genotoxical study. Environ Sci Technol. 2006; 40(14):4367-4373.

43. Chithrani BD, Chan WC. Elucidating the mechanism of cellular uptake and removal of protein-coated gold nanoparticles of different sizes and shapes. Nano Lett. 2007;7(6):1542-1550.

44. Yallapu MM, Othman SF, Curtis ET, Gupta BK, Jaggi M, Chauhan SC. Multi-functional magnetic nanoparticles for magnetic resonance imaging and cancer therapy. Biomaterials. 2011;32(7):1890-1905. 
45. Elkin SR, Bendris N, Reis CR, et al. A systematic analysis reveals heterogeneous changes in the endocytic activities of cancer cells. Cancer Res. 2015;75(21):4640-4650.

46. Chen J, Luo Z, Zhao Z, Xie L, Zheng W, Chen T. Cellular localization of iron (II) polypyridyl complexes determines their anticancer action mechanisms. Biomaterials. 2015;71:168-177.
47. Brunner TJ, Wick P, Manser P, et al. In vitro cytotoxicity of oxide nanoparticles: comparison to asbestos, silica, and the effect of particle solubility. Environ Sci Technol. 2006;40(14):4374-4381.

48. Kohler N, Sun C, Wang J, Zhang M. Methotrexate-modified superparamagnetic nanoparticles and their intracellular uptake into human cancer cells. Langmuir. 2005;21(19):8858-8864. 


\section{Supplementary materials}
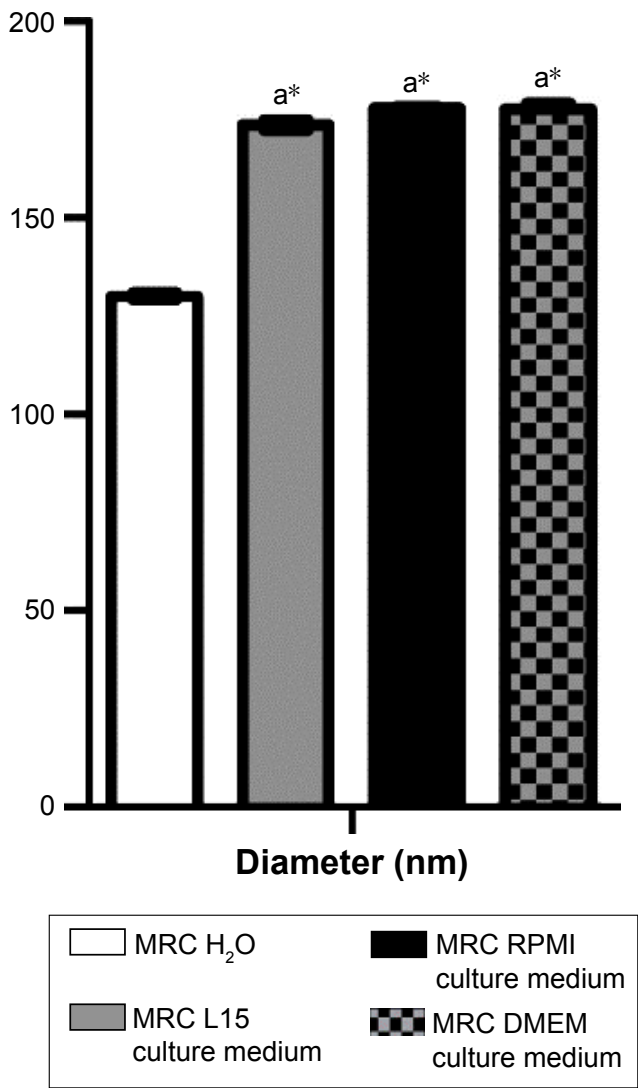

Figure SI Hydrodynamic diameter analysis in culture media.

Notes: Maghemite-rhodium citrate (MRC) diluted in culture medium had larger hydrodynamic diameter than in water dilution $\left(a^{*}\right)$. There was no difference among hydrodynamic diameters of MRC diluted in LI5, RPMI, and DMEM culture medium.

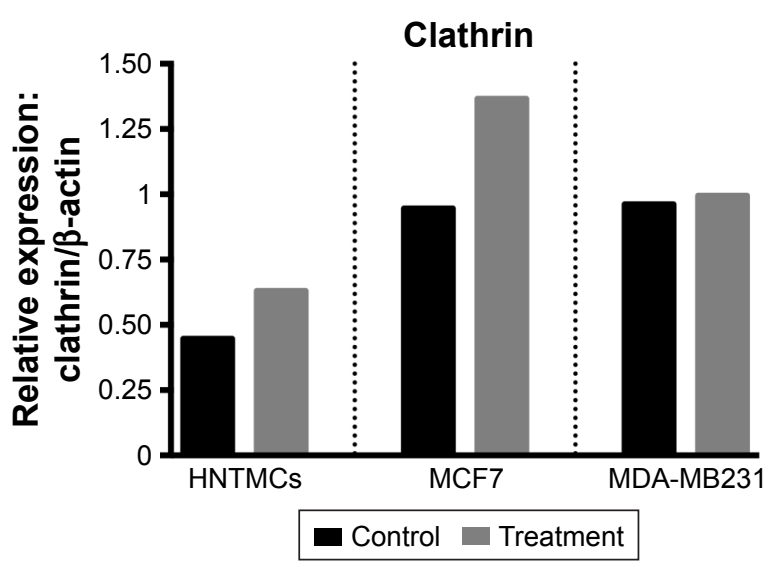

Figure S2 Relative densities of clathrin bands.

Note: Bands in human nontumor mesenchymal cells (HNTMCs), MCF7, and MDAMB23 I cells after 6 hours of exposure of maghemite-rhodium citrate nanoparticles (treatment) in gray bars and control group in black bars (normalized to $\beta$-actin, protein loading control).

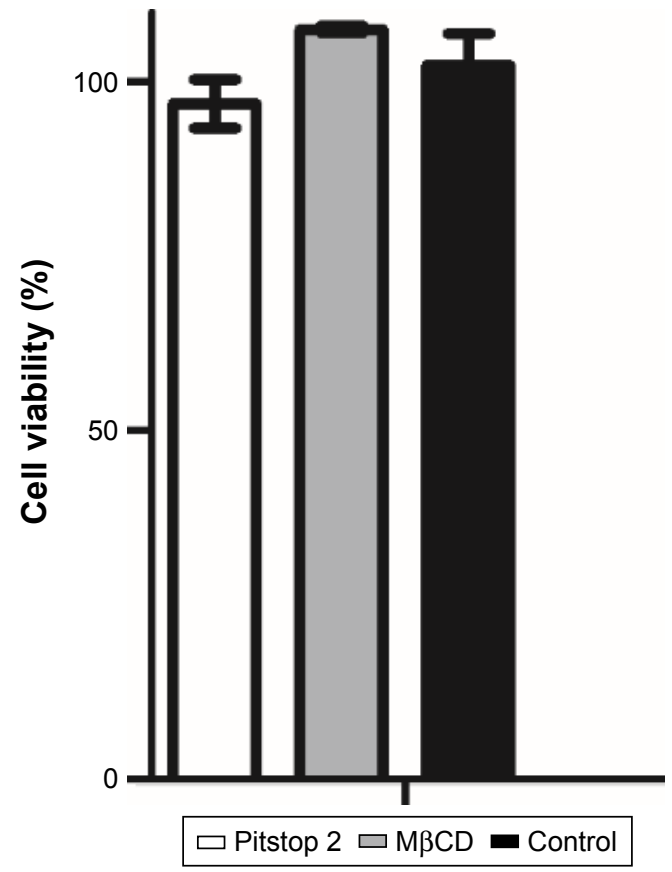

Figure S3 Endosome inhibitor-cytotoxicity analysis. Cell viability analyzed by MTT did not show viability reduction after 2 hours' exposure.

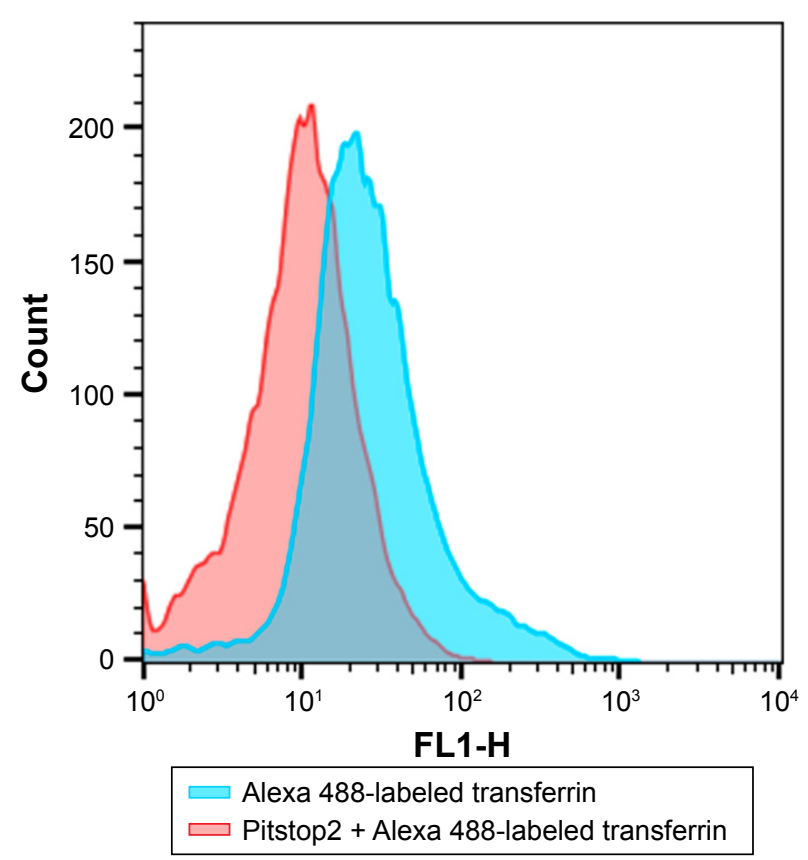

Figure S4 Clathrin inhibition. Alexa 488-labeled transferrin-uptake reduction after Pitstop2 inhibition of clathrin. 


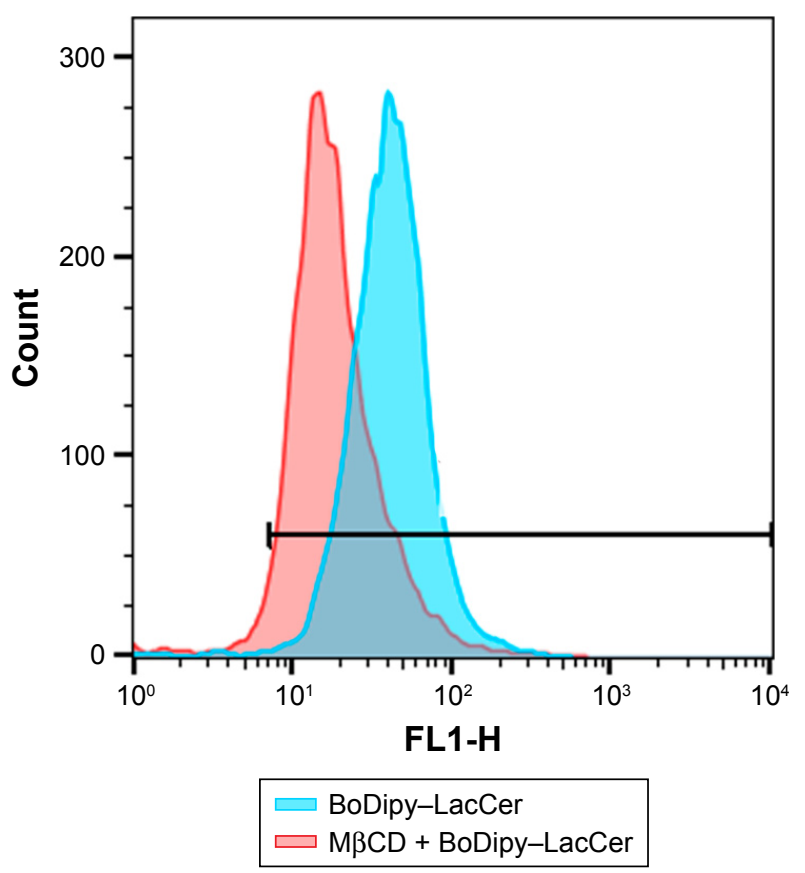

Figure S5 Caveolin inhibition. BoDipy-LacCer-uptake reduction after M $\beta C D$ inhibition of caveolin.

\section{Publish your work in this journal}

The International Journal of Nanomedicine is an international, peerreviewed journal focusing on the application of nanotechnology in diagnostics, therapeutics, and drug delivery systems throughou the biomedical field. This journal is indexed on PubMed Central, MedLine, CAS, SciSearch ${ }^{\circledR}$, Current Contents ${ }^{\circledR} /$ Clinical Medicine,
Journal Citation Reports/Science Edition, EMBase, Scopus and the Elsevier Bibliographic databases. The manuscript management system is completely online and includes a very quick and fair peer-review system, which is all easy to use. Visit http://www.dovepress.com/ testimonials.php to read real quotes from published authors.

\footnotetext{
Submit your manuscript here: http://www.dovepress.com/international-journal-of-nanomedicine-journal
} 